\title{
Scanning Electron Microscopy of Staphylococcus aureus Exposed to Some Common Anti-staphylococcal Agents
}

\author{
By D. GREENWOOD AND F. O'GRADY \\ Department of Bacteriology, St Bartholomew's Hospital, London, E.C. I
}

(Accepted for publication 3 November I97I)

SUMMARY

The effects of cloxacillin, fusidic acid, lincomycin, erythromycin and novobiocin on a strain of Staphylococcus aureus were examined. Morphological effects of antibiotic action were observed in the scanning electron microscope on samples taken from cultures continuously monitored photometrically.

Cloxacillin caused surface changes similar to those previously reported with ampicillin and gave an opacity trace indicating slow lysis of the cells. Fusidic acid, lincomycin and erythromycin all caused total collapse of many of the cells which was reflected by an abrupt lytic phase on the opacity trace. Novobiocin gradually inhibited growth and led to bizarre, atypically dividing bacteria.

\section{INTRODUCTION}

The scanning electron microscope offers a relatively simple method of studying the surface morphology of micro-organisms at high magnification with a resolution approaching I 5 to $20 \mathrm{~nm}$ under optimal conditions. One of the potentials of the instrument which remains largely unexplored is in the study of the morphological consequences of exposure of bacteria to antimicrobial agents. In previous communications we have reported morphological changes in Staphylococcus aureus and Streptococcus pyogenes induced by ampicillin (Greenwood \& O'Grady, I969a) as well as a wide variety of responses of Gram-negative bacilli to the same agent (Greenwood \& O'Grady, I969 b; O'Grady et al. 1970).

We have now extended our scanning electron microscope observations by examining morphological changes in staphylococci exposed to a number of anti-staphylococcal agents in clinical use.

\section{METHODS}

Organism. A strain of Staphylococcus aureus isolated in the diagnostic hospital laboratory was used. The strain produced penicillinase, but was sensitive, on plate testing with impregnated discs, to fusidic acid, erythromycin, lincomycin, cloxacillin and novobiocin.

Antibiotics. Cloxacillin (Orbenin, Beecham Research Laboratories, Brentford, Middlesex), novobiocin (Albamycin, Upjohn Ltd, Crawley, Sussex), erythromycin lactobionate (Erythrocin i.v., Abbott Laboratories Ltd, Queenborough, Kent), sodium fusidate (Fucidin, Leo Laboratories Ltd, Hayes, Middlesex) and lincomycin hydrochloride (Lincocin, Upjohn Ltd) were used. Dilutions were made as required in sterile distilled water. Minimum inhibitory concentrations (MIC) of these agents were determined by serial doubling dilutiontube titration in nutrient broth.

Conditions of culture and exposure to antibiotics. In order to maintain a high population density for subsequent morphological examination while ensuring that the cultures were in the exponential phase of growth, broth cultures of the Staphylococcus aureus were monitored 

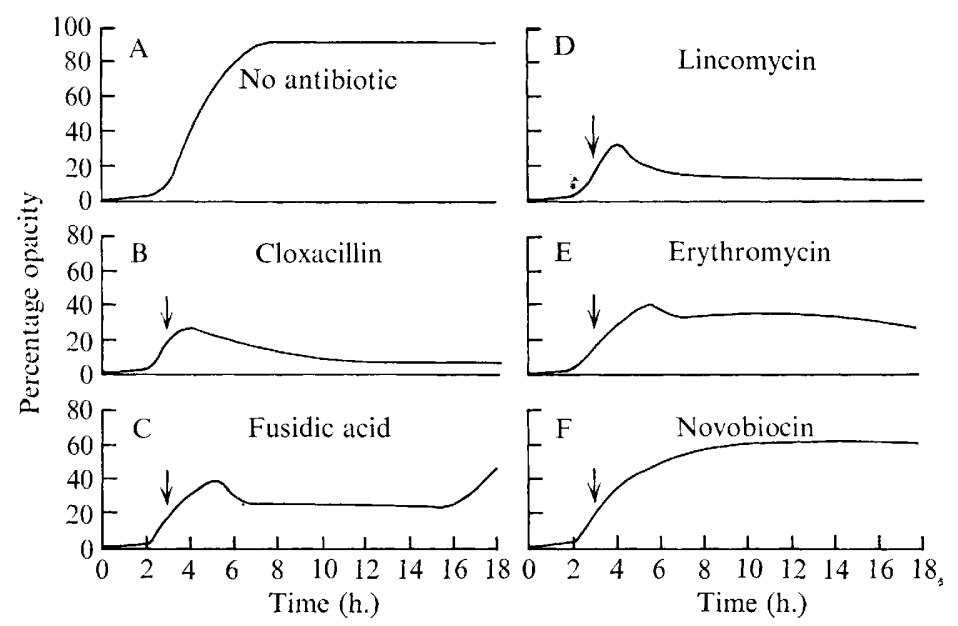

Fig. 1. Continuous optical density records of the Staphylococcus aureus strain used for the morphological studies. A, normal growth curve; B-F, antibiotic added at arrow.

Table I. Minimum inhibitory concentrations' of the various agents for the strain of Staphylococcus aureus used

$\begin{array}{lc}\text { Antibiotic } & \text { MIC }(\mu \mathrm{g} / \mathrm{ml}) \\ \text { Cloxacillin } & 0.3 \\ \text { Fusidic acid } & 0.3 \\ \text { Lincomycin } & \mathrm{I} \cdot 2 \\ \text { Erythromycin } & 0.6 \\ \text { Novobiocin } & 0.3\end{array}$

using a simple photometer giving a continuous record of opacity (Watson, Gauci, Blache \& O'Grady, 1969). The cultures were mixed with a magnetic stirrer. Antibiotic was added to give a concentration of approximately ro times the MIC when a point was reached on the growth curve equivalent to the mid-to-late logarithmic phase of growth (viable count approximately $10^{7}$ organisms $/ \mathrm{ml}$ ).

Fixation and preparation for scanning electron microscopy. Two $\mathrm{ml}$ specimens were removed immediately before adding the antibiotic, and at intervals afterwards, the bacteria were fixed overnight with an equal volume of $2 \%$ glutaraldehyde in $5 \%$ sucrose. The specimens were prepared for scanning electron microscopy as previously described (Greenwood \& O'Grady, I969a).

\section{RESULTS}

The minimum inhibitory concentrations of the various antibiotics against the strain of Staphylococcus aureus used are shown in Table I.

Normal Staphylococcus aureus. The normal growth curve of the $S$. aureus as obtained in our opacity-monitoring system is shown in Fig. I A. The scanning electron microscope appearance of normal bacteria of this strain is shown in Fig. 2. The bacteria were roughly spherical and, as far as can be judged at the resolution achieved, smooth. Some samples yielded bacteria with small surface depressions (Fig. 3), but this may have been a vacuum 

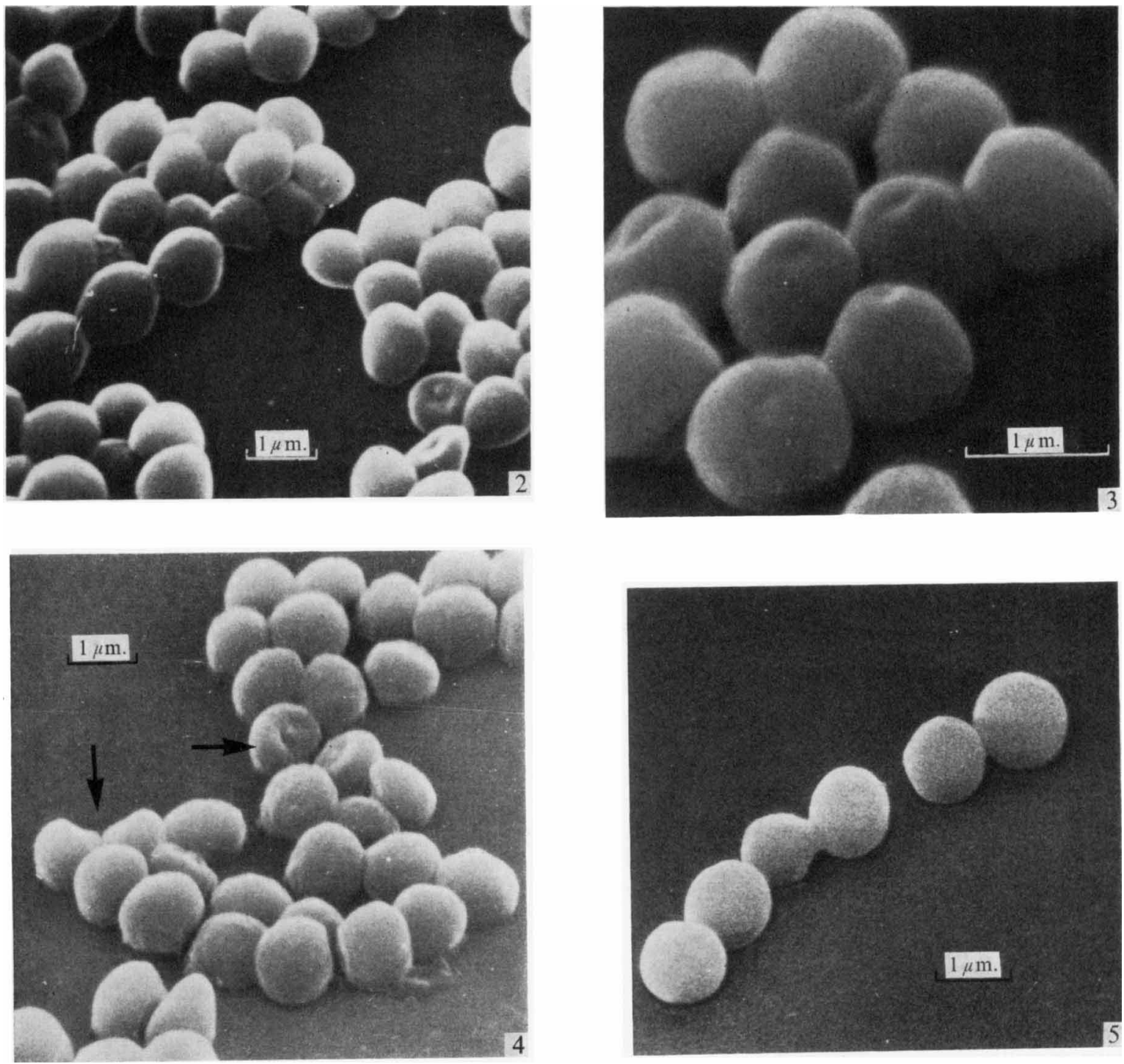

Fig. 2. Normal Staphylococcus aureus cells from mid-to-late logarithmic growth phase.

Fig. 3. Staphylococcus aureus showing small surface depressions.

Fig. 4. Terminal stages of division in Staphylococcus aureus. The arrows indicate a pair of bacteria joined centrally just before division and a pair evidently having finally separated in the act of drying on the coverslip.

Fig. 5. Division in Staphylococcus aureus evidently proceeding by progressive ingrowth of wall.

artifact. Two appearances were seen in dividing bacteria, one of which suggested that division generates two roughly hemispherical bacteria ultimately joined at a single central point (Fig. 4), and the other that there is progressive separation of the two bacteria in a manner fundamentally similar to that seen in streptococci (Fig. 5). 


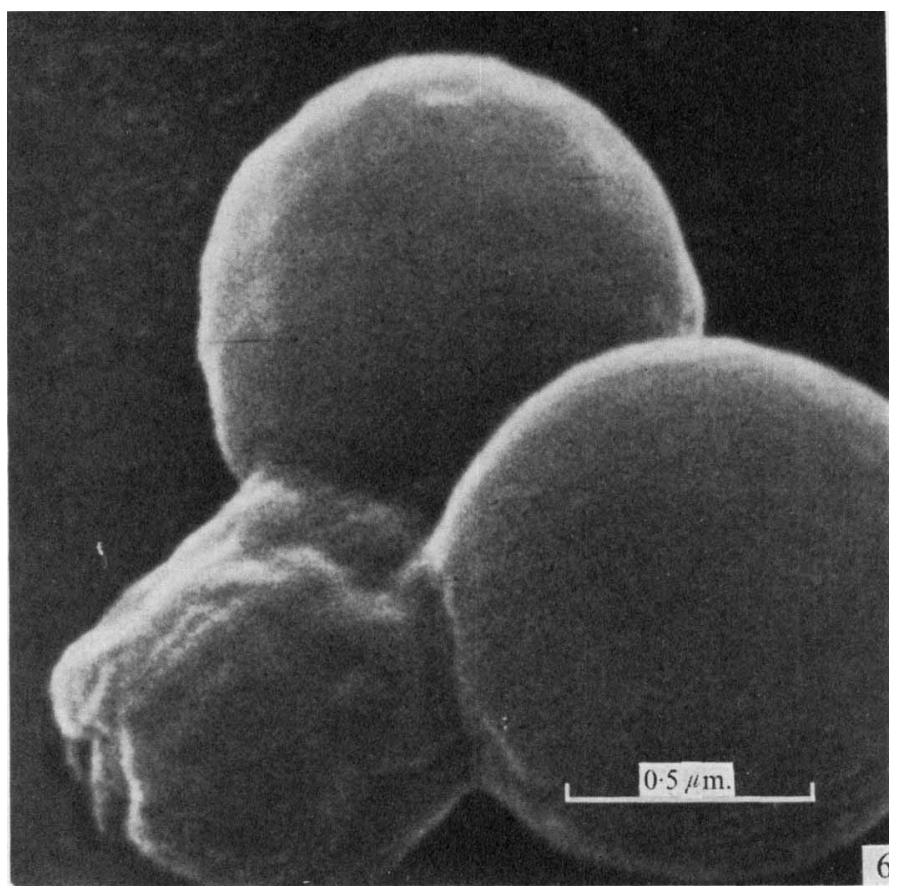

Fig. 6. Triad of Staphylococcus aureus cells following exposure to cloxacillin, $3 \mu \mathrm{g} / \mathrm{ml}$ for $3 \mathrm{~h}$.

Penicillins. The effect of penicillins on the opacity of Staphylococcus aureus cultures is illustrated in Fig. I B which shows the result of adding cloxacillin to a growing culture. The destructive changes induced by ampicillin on penicillin-sensitive strains as viewed in the scanning electron microscope have been reported elsewhere (Greenwood \& O'Grady, I969a). Other penicillins seem to have a similar effect. A striking appearance frequently seen, particularly at the relatively high population densities we were using, is illustrated in Fig. 6. Here cells of a triad exposed to cloxacillin are evidently physically joined, yet apparently only one member of the group has been affected by the penicillin.

Fusidic acid, lincomycin and erythromycin. All three of these antibiotics caused inhibition of growth followed by lysis of the cells. This is shown on the opacity trace (Fig. I C, D, E) by an immediate deviation from the normal growth curve which was later followed by a phase in which the opacity suddenly decreased before levelling off to a stable value. Opacity due to the growth of genotypically resistant variants increased after a variable length of time after exposure to fusidic acid, but this did not occur with erythromycin or lincomycin during the $24 \mathrm{~h}$ period of observation of our experiments.

In the scanning electron microscope the appearance of bacteria exposed to each of these agents was very similar. Figure 7 shows bacteria beginning to collapse after exposure to fusidic acid for $\mathrm{I} \mathrm{h}$, and the total collapse of many bacteria on further exposure is seen in Fig. 8. This Fig. also illustrates the frequently seen collapse of bacteria on both sides of an internal structure (presumably a septum) which in some cases appeared to have divided. The collapse of bacteria due to lincomycin and erythromycin (Fig. 9-r2) seems very similar, though in isolated preparations we have demonstrated a discrete lesion due to lincomycin (Fig. 10) and partial collapse giving a 'doughnut' appearance due to erythromycin (Fig. I2). 


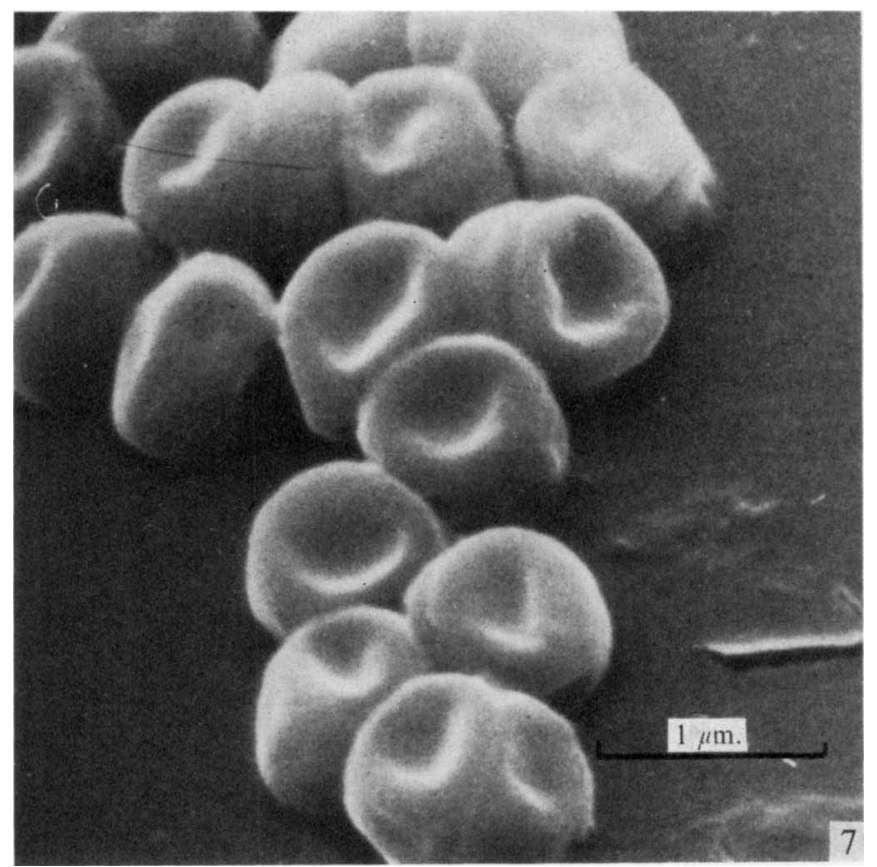

Fig. 7. Effect of exposure of Staphylococcus aureus to fusidic acid, $3 \mu \mathrm{g} / \mathrm{ml}$ for $\mathrm{I} \mathrm{h}$.

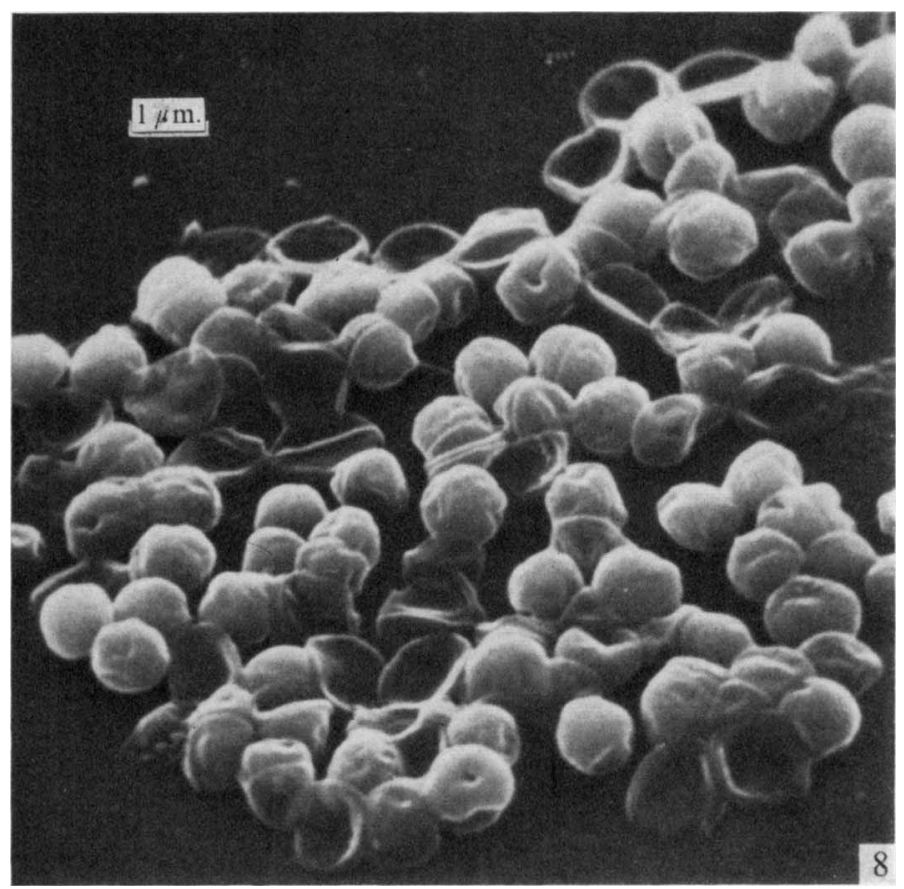

Fig. 8. Effect of exposure of Staphylococcus aureus to fusidic acid, $3 \mu \mathrm{g} / \mathrm{ml}$ for $3 \mathrm{~h}$. The collapse of some bacteria across an internal septum, which in some instances appears to have divided, is clearly seen. 

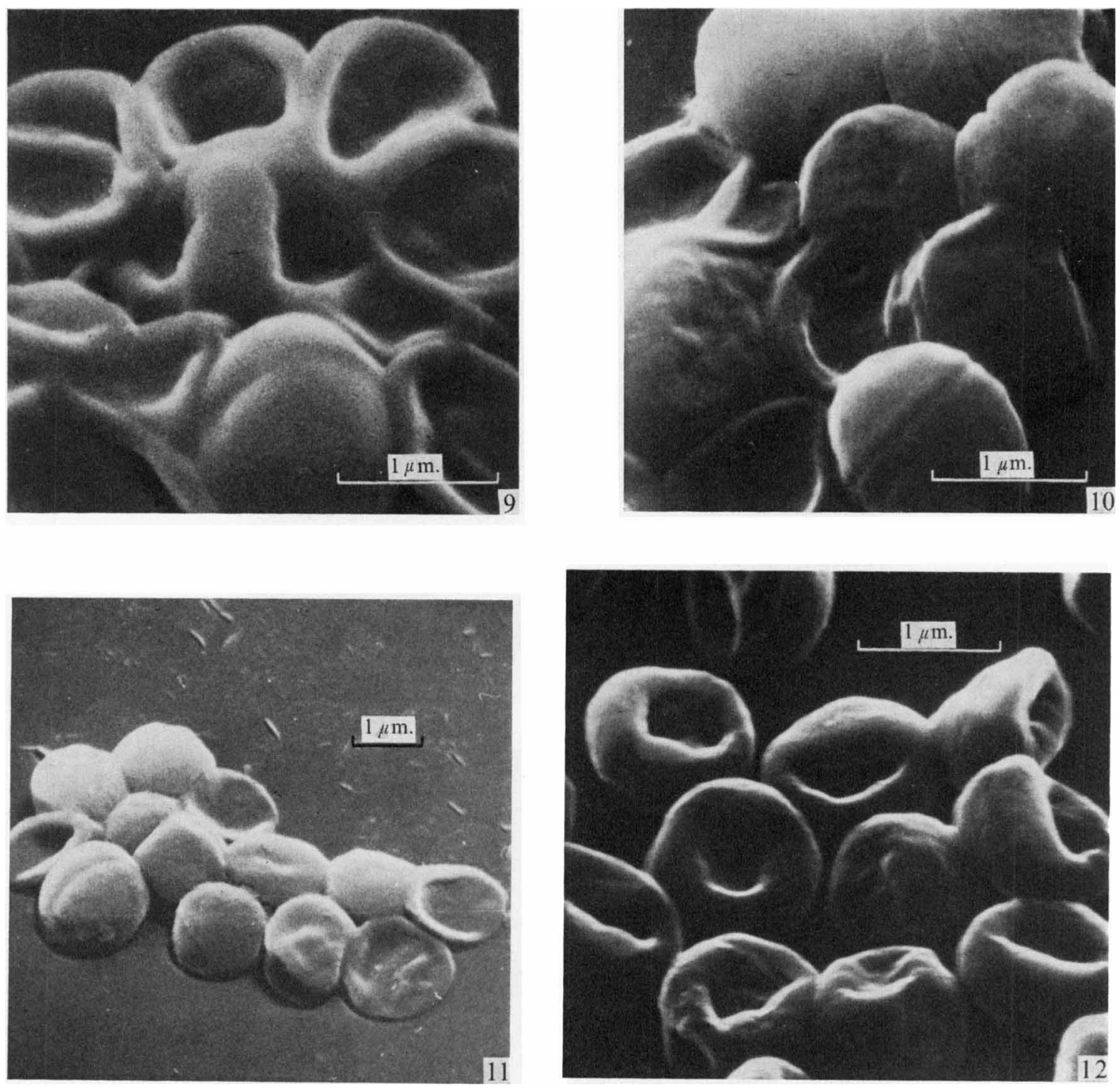

Fig. 9, IO. Effect of exposure of Staphylococcus aureus to lincomycin, $12 \mu \mathrm{g} / \mathrm{ml}$, for $3 \mathrm{~h}$. The collapsed bacterium in the centre of the field (Fig. 10) contains an apparent hole in the cell surface.

Fig. I I, I2. Effect of exposure of Staphylococcus aureus to erythromycin, $6 \mu \mathrm{g} / \mathrm{ml}$, for $3 \mathrm{~h}$. The different appearances were found in separate experiments.

We have not been able to ascertain whether these latter appearances are characteristic of the different antibiotics but it is possible that they are demonstrable with each of these agents under suitable conditions.

Novobiocin. When the Staphylococcus aureus strain was exposed to novobiocin, the opacity trace showed a gradual inhibition of growth, but no subsequent lysis was observed (Fig. I F). Morphological consequences of exposure to this antibiotic can be seen in Fig. I3. Bizarre bacteria abounded, varying markedly in size and shape, many being smaller than 


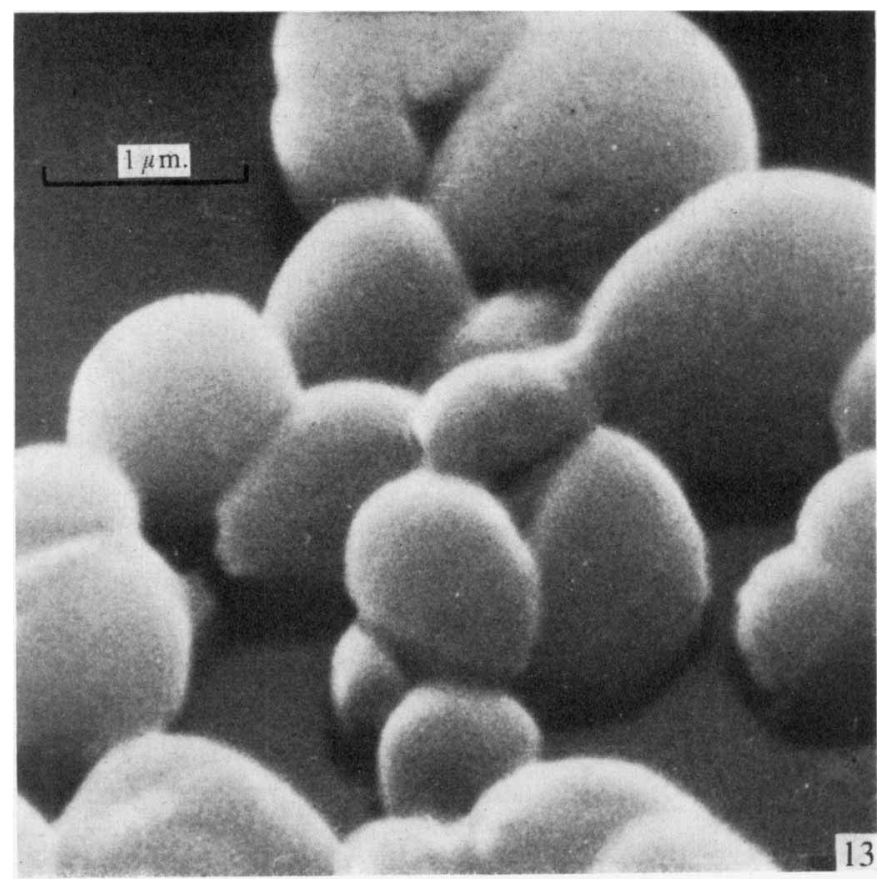

Fig. I3. Effect of exposure of Staphylococcus aureus to novobiocin, $3 \mu \mathrm{g} / \mathrm{ml}$ for $3 \mathrm{~h}$.

usual, others being abnormally large. No surface defects as such were seen, nor did division appear to be completely inhibited, numerous incipient division points being visible.

\section{DISCUSSION}

Apart from our own previous studies (Greenwood \& O'Grady, I969a, $b$; O'Grady et al. I970) and a recent paper by Klainer \& Perkins (1970) the use of the scanning electron microscope to observe morphological consequences of antibiotic action on micro-organisms remains unexplored.

Our results further indicate that the instrument has a useful potential in this field. Even in the study of normal organisms the scanning electron microscope has useful information to offer. For example, our observations demonstrate the two modes of cleavage in Staphylococcus aureus, discussed by Elek (1959). At what point these bacteria become functionally separate entities is uncertain. The effect illustrated after exposure to cloxacillin (Fig. 6), where only one bacterium of a triad was apparently affected by the antibiotic would seem to indicate that the bacteria are independent though joined. On the other hand, examples can be seen in Fig. 8 of bacteria exposed to fusidic acid which have collapsed across a septum which has evidently already divided. Surface appendages and intercellular bridges such as those described by Klainer \& Betsch (1970) were only very occasionally seen and did not seem to be associated with the division process or the clustering of staphylococci as these authors suggested. Our observations tend to support the traditional view that staphylococcal clumps arise from random divisions occurring in different planes.

Fusidic acid, lincomycin and erythromycin all gave rise to a very similar lesion from which susceptible bacteria totally collapsed. Perhaps this effect was exaggerated by the high 
vacuum needed in the electron microscope, but it is clear from comparison with normal bacteria that progressive structural weakness was caused corresponding to the decrease in opacity demonstrable by turbidometric methods. Furthermore, after exposure of staphylococci to these agents, morphologically abnormal bacteria were visible in the light microscope.

Fusidic acid and erythromycin are thought to act by interrupting translocation of peptidyltRNA on $70 S$ ribosomes and lincomycin probably also acts by interfering with this or a closely related step. All three of these agents have considerable bactericidal activity and it remains obscure why this should be so. Preliminary studies in the light microscope with other inhibitors of protein synthesis such as chloramphenicol and tetracycline (which in contrast to the other agents is thought to act on the $30 S$ ribosomal sub-unit) has indicated that cell collapse is caused by these antibiotics as well. What accounts for these secondary destructive changes remains problematical, but it is curious that these substances, so markedly different in their molecular structure, should produce such similar lesions after interference with separate steps in the process of protein synthesis.

A number of morphological effects of exposure of micro-organisms to novobiocin have been reported, including filament formation in Gram-negative bacilli (Smith, Dietz, Sokolski \& Savage, 1956) and chain formation in Streptococcus faecium (Brock, 1967). The morphological changes we report are probably analogous to these effects. Division continues for a short time before inhibition by novobiocin is complete (Brock, 1967) and it is possible that during this time control of the division process is impaired, giving rise to the bizarre shapes we have observed.

These results show the value of the scanning electron microscope in studying the effects of antibiotics on micro-organisms. Information about the mode of action is not, of course, obtained - that is the province of the biochemist - but direct observation of morphological changes following antibiotic action may reveal hitherto unsuspected secondary effects such as those we have demonstrated using fusidic acid, lincomycin and erythromycin. These changes are not adequately seen in the light microscope, while the high magnifications and three-dimensional effect obtained with the scanning electron microscope make it ideal for this purpose.

This work was supported in part by a grant from Leo Laboratories Ltd.

\section{REFERENCES}

Brock, T. D. (1967). In Antibiotics, vol I, p. 651. Edited by D. Gottlieb \& P. D. Shaw. Berlin and New York: Springer-Verlag.

ELEK, S. D. (1959). Staphylococcus pyogenes, p. 37. Edinburgh: E. S. Livingstone.

GreENwood, D. \& O'GRADY, F. (1969a). Antibiotic-induced surface changes in micro-organisms demonstrated by scanning electron microscopy. Science, New York 163, 1076-1078.

GreenwoOd, D. \& O'Grady, F. (I969 b). A comparison of the effects of ampicillin on Escherichia coli and Proteus mirabilis. Journal of Medical Microbiology 2, 435-441.

KlatNeR, A. S. \& BetSCH, C. J. (1970). Scanning-beam electron microscopy of selected micro-organisms. Journal of Infectious Diseases 12r, 339-343.

Klainer, A. S. \& Perkins, R. L. (1970). Antibiotic-induced alterations in the surface morphology of bacterial cells: A scanning-beam electron microscopy study. Journal of Infectious Diseases 122, 233-328.

O'Grady, F., Greenwood, D., Hammond, B., Mackintosh, I. P. \& Watson, B. W. (1970). Effects of penicillins on enterobacteria in mechanical systems simulating conditions of bacterial growth in the urinary tract. Proceedings of Anglo-Soviet Symposium on Semi-synthetic Penicillins. (In the press.)

Smith, C. G., Dietz, A., Sokolski, W. T. \& Savage, G. M. (I956). Streptonivicin, a new antibiotic. Antibiotics and Chemotherapy 6, 135-142.

Watson, B. W., Gauci, C. L., Blache, L. \& O'Grady, F. W. (I969). A single turbidity cell for continously monitoring the growth of bacteria. Physics in Medicine and Biology 14, 555-558. 